\title{
Social distancing, boredom and alcohol during Covid-19. A research in Italy on a sample of university students.
}

\author{
Nicola Malizia* \\ *Associate Professor of Sociology of Law, Deviance and Social Change, Faculty of Sciences of Man and Society, University of Enna \\ "Kore" - Italy. \\ Italy: telephone +393346386572. \\ Correspondence to: nicola.malizia@unikore.it \\ DOI: 10.29322/IJSRP.11.06.2021.p11449 \\ http://dx.doi.org/10.29322/IJSRP.11.06.2021.p11449
}

\begin{abstract}
This study explored the drinking behavior of a sample of 351 Italian university students during COVID-19 to understand whether social isolation imposed to avoid contagion led to an increase or decrease in alcohol consumption at the individual level with repercussions on university performance; finally, the research aimed to investigate whether or not boredom influenced drinking behavior during the period under study. Data were drawn from a study of 351 Italian university students. The Alcohol Use Disorders Identification Test (AUDIT) and a self-report questionnaire were used for this purpose. Data were collected from March 2020 to March 2021 and processed with MathLab 2020. Response rates were 100\% ( $=351)$. The data obtained show high rates of connection between the 3 different alcohol styles (AUDIT) and low college performance. Similar results pertain to the relationship between boredom and alcohol behavior during the Covid-19. The research has limitations due to the relatively small sample size and it is hoped that more robust research in the future will confirm the estimates obtained or produce new results. The results of the study conducted in Italy on a sample of university students $(\mathrm{N}=351)$ revealed significant data regarding alcoholic behavior related to social isolation with repercussions on university performance and boredom during the pandemic. It is necessary to revise state policies to contain the phenomenon of alcohol/youth and inform them about the risks to their health. Alcohol use was considered to be extremely detrimental to the individual and their life course.
\end{abstract}

Keywords: Covid-19, Alcohol behavior, university students, boredom, deviance.

\section{Introduction}

Alcohol use represents, according to sociological literature, a deviant act, and is normally perceived as the result of an individual state of social disorganization, a failure of the subject to integrate with society's values, or temporary situations of stress (Censi et al. 2019). Alcohol use, especially in youth, becomes a social phenomenon that has significant connections to cultural, social, familial, and individual backgrounds (Calamai 2018). The COVID-19 pandemic has impacted individuals, families, and communities worldwide. Psychologists believe that individual reactions to the pandemic are comparable to a traumatic event, a war or disaster (Panagiotidis et al. 2020), and take positive and negative forms of coping in daily life. Recent studies have shown an upward trend in alcohol use during COVID-19 as a psychological comfort substance (Ornell et al. 2020) and an overall worldwide increase in alcohol sales by March 2020 (Martin 2020). Increased alcohol use as individual self-care is a temporary solution, but not a long-term one (SAMSHA 2020). Intrafamily conflict, depression, anxiety, stress, emotional swings, irritability, and low tolerance are also linked to increased alcohol use (Lyers et al. 2020; Lin et al. 2020; Galea et al. 2020; Sola et al. 2019; Bränström and Pachankis 2018; Hassel et al. 2013). The consequences of the COVID-19 pandemic on the psychological health and well-being of individuals have been extensively studied (Walker et al. 2020). Recent research has shown that people with high levels of coronavirus anxiety exhibited hopelessness and suicidal ideation (McIntyre and Lee 2020). A recent survey in China showed that 53.8\% of participants experienced moderate to severe psychological impact with the outbreak: $17.4 \%$ experienced moderate to severe depressive symptoms and $28.8 \%$ experienced moderate to severe anxiety symptoms ( $\mathrm{Li}$ et al. 2020). In addition, another study in China during the pandemic showed that 35\% of participants experienced psychological distress (Qiu et al. 2020). It should be 
noted that alcohol consumption makes a person more vulnerable to disease and in particular COVID-19 infection and no level of alcohol consumption improves health (Burton \& Sheron 2018). Alcohol abuse is also a risk factor for pneumonia and other lung infections and the development of acute respiratory distress syndrome (ARDS), which is a major complication of Covid-19. The inclusion of a health goal to strengthen the prevention and treatment of substance use disorders in the 2030 Sustainable Development Goals (SDG 2030) agenda is an important recognition of the negative effects of alcohol use. According to Scott et al. (2020), alcohol use is associated with problems that vary by age; harms are greater for young adults (18 to 24 years old) than for older adults ( 25 years and older). Recent studies show that frequent alcohol use is prevalent in younger populations (National Institute of Drug Abuse (NIDA) 2019). Although the relationship between alcohol use and social, ecological, and cultural conditions has been studied in the past, there is now a need to investigate new mechanisms that drive young people to use alcohol: the ongoing pandemic may be an area of study and research to understand how individuals respond or why they commit deviant acts. In Durkheim's (2008) theory of suicide, alcohol is identified as an individual causal factor and not a socio-cultural factor. In contrast, according to Merton (1966), alcohol is an expression of protest over the inadequate relationship between cultural goals and institutional means. This research also explored the relationship between boredom and alcohol, with reference to the pandemic. When boredom determines the transition to the deviant act, it is necessary to analyze the internal (personal) and external (social factors) forces that guided and determined this behavior. In a modern context such as the pandemic, boredom, linked to the condition of social isolation especially of young people, can turn into different reactions, such as the voluntary abandonment of institutional paths (university and related studies), the non-acceptance of the current social configuration, the need to achieve new goals or risk, the use of alcohol or drugs to defeat social loneliness (Orgilès et al. 2020). Regarding the relationship (not during the pandemic) between college students and alcohol use, it is worth noting a U.S. study of knowledge of and attitudes toward current alcohol rules on college campuses that shows most new students are aware of the restrictions, but less than half are willing to accept them (Cao et al. 2020). Sargent et al. (2020) also argue that a culturally marked society drives individuals to use psychoactive substances (including alcohol) that promise well-being. The relationship between pandemic (enforced social isolation) and alcohol has contributed, especially in 2020 to change many theoretical approaches on so-called "drinking styles": The "convivial style", characterized by the pursuit of pleasure in being together, and the "homogenizing group style" in which alcohol plays the role of homogenizing the individual to the group have disappeared, reinforcing the tendency to drink alone at home (Corbin et al. 2020).

\section{Methods}

Data were drawn from a study of 351 Italian university students with the aim of understanding whether the pandemic, imposed restrictions, and related boredom increased alcohol consumption with consequences for university performance. The Alcohol Use Disorders Identification Test (AUDIT) and a self-report questionnaire were used for this purpose. The AUDIT includes questions about the consequences of alcohol use, along with questions about the amount and frequency of intake. It consists of 10 items, with 5 possible answers, scored from 0 to 4 , except items 9 and 10, which have only a score of $0,2,4$. The result is obtained by summing the scores of the domains: risk-free consumption, hazardous consumption, and dependence. The AUDIT and self-report questionnaire were administered at the end of the online classes (distance learning). Each participant was given a time limit of 30 minutes. The questionnaire covers a wide range of topics including: individual and personal data (single, married, engaged, separated); problems with participation in university activities and poor performance; psychological, family, social and personal problems; In the present research, particular attention was paid to "alcohol behaviors related to university performance "during Covid-19 and the relationship between boredom, as a consequence of social isolation imposed to prevent COVID-19 infections, and alcohol. Data were collected from March 2020 to March 2021 and processed in April 2021. Informed consent was obtained for participation in all phases of this study; participation was completely free and voluntary; no reward or compensation was obtained by the student. The research method and the questionnaire administered online were reviewed and approved by the University of Enna "Kore" - Italy. All information was treated with the utmost confidentiality. The main aspect that was highlighted as particularly important for the validity of the questionnaire was the students' trust in the anonymity of their answers. The description of the results was based on descriptive statistical techniques and tools, using Mathlab 2020, depending on the type of variable. Our target population consisted of Kore University students aged 18 years and older, residing in households in EU member states. Although the age range of the university population varies widely, the vast majority of university students $(87.13 \%)$ are between the ages of 18 and 26; therefore, we focused our analysis on this age range. 
Fig.1

Individual data. Italian university students sample (alcohol during Covid-19 year 2020-2021) $(N=351)$

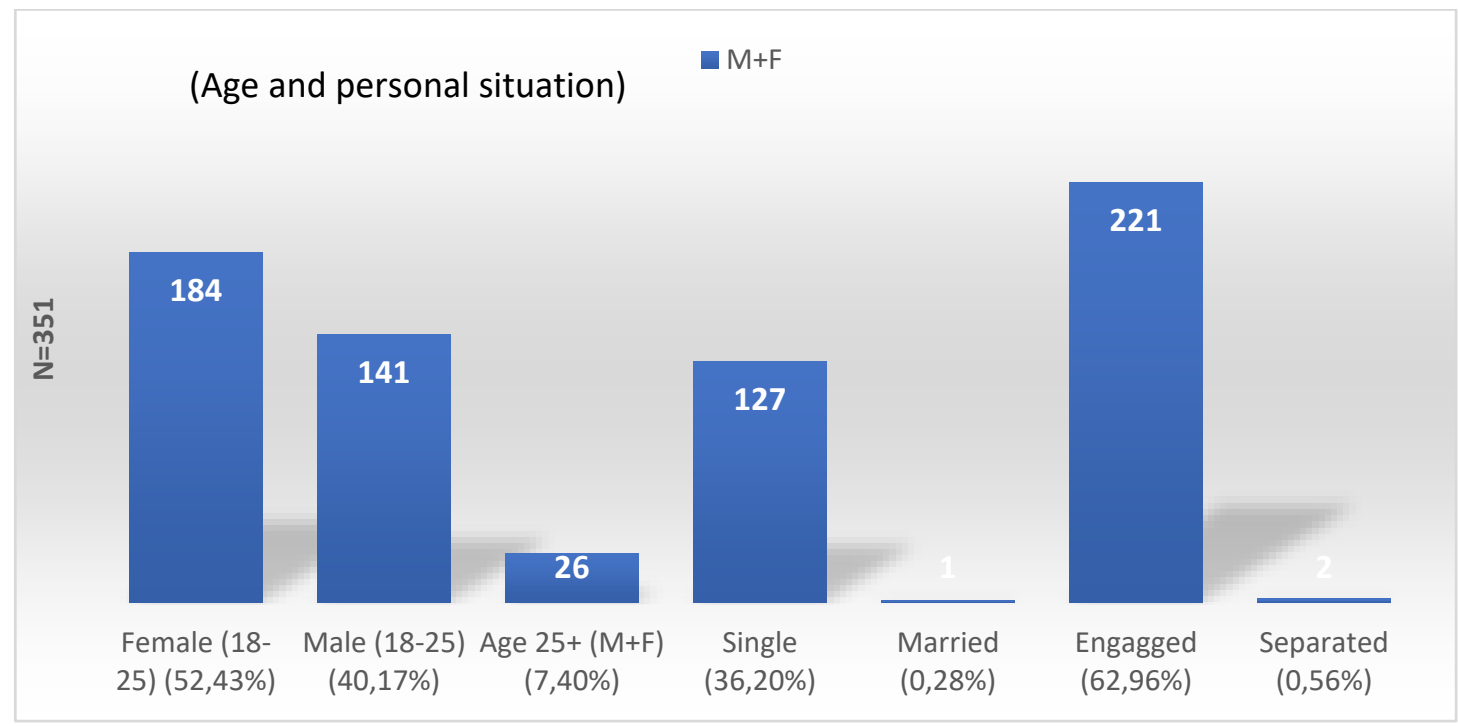

Fig. 2

Academic problems and their correlation with the AUDIT. Alcohol and low academic performance during Covid-19. Year 2020-2021 - Italy (N=351) 


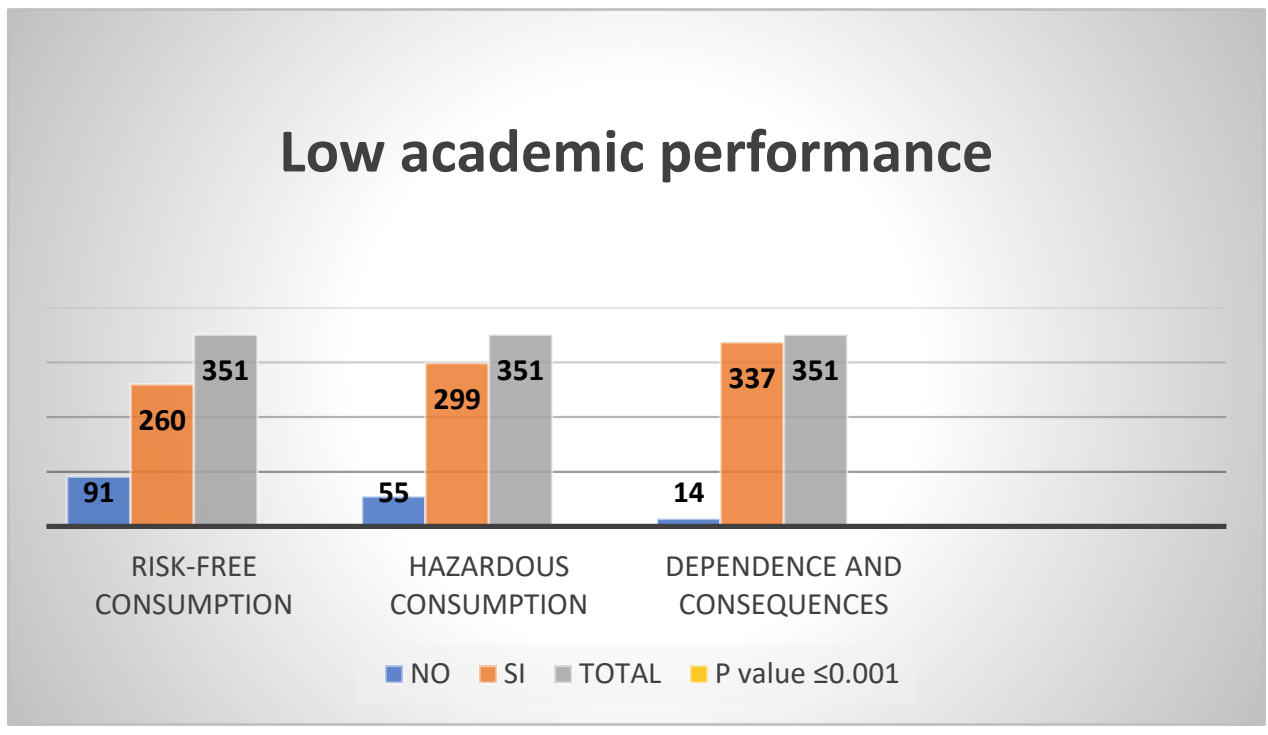

Fig. 3

Boredom and alcohol in italian university students $(N=351)$ during Covid-19 (correlation with the AUDIT) Year 2020/2021

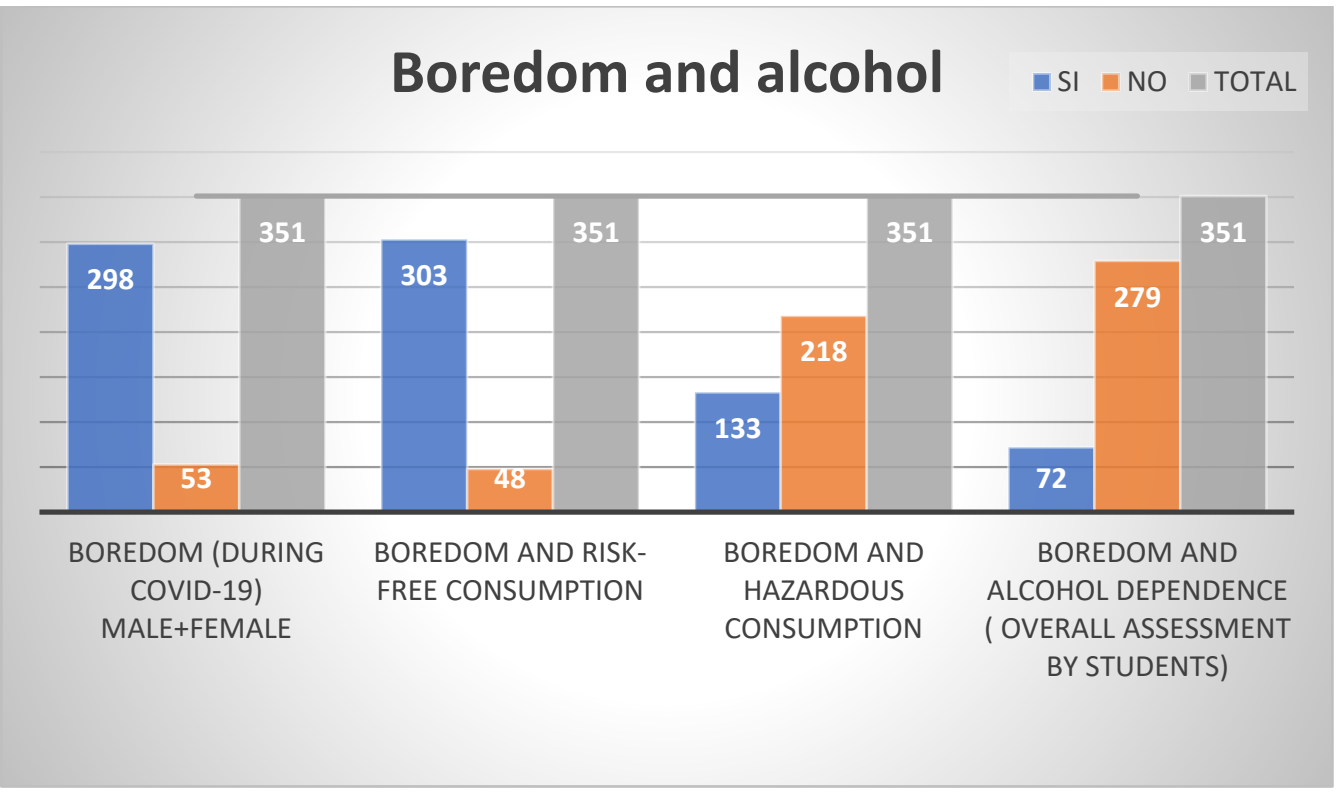

\section{Results}

Response rates were $100 \%(\mathrm{n}=351)$. Informed consent was obtained. Students were instructed online and verbally (as described on the first page of the questionnaire sent out for the survey) that they were not to enter their names or other 
identifying marks on the questionnaire. The age range (Fig.1) varied as follows: for females from 18-25 (184=52.43\%), for males from 18-25 $(141=40.17 \%)$, and for others over $25(26=7.40 \%)$. Their personal circumstances were also investigated: single were 127 (36.20\%); married were 1 (0.28\%); those in a relationship were $221(62.96 \%)$; and separated were 2 $(0.56 \%)$. The first step of the research was directed to investigate the correlation between alcoholic conduct (AUDIT) and possible low college performance, during Covid-19. The data obtained show that out of $\mathrm{N}=351$ students in the sample under investigation $\mathrm{N}=91(25.93 \%)$ stated that they had used "hazardous alcohol", thus excluding any impact of alcohol on their university performance during the pandemic period, while $\mathrm{N}=260(74.07 \%)$ responded that alcoholic behavior impaired overall university performance. Regarding the "hazardous consumption" of alcohol, $\mathrm{N}=55$ (15.67\%) responded that such behavior had no impact on college performance, while $\mathrm{N}=299(85.19 \%)$ responded "yes," linking hazardous alcohol consumption to low college performance. Finally, with regard to "alcohol dependence," the research sought to investigate knowledge of the risks of alcohol "dependence" on college performance: $\mathrm{N}=14$ (3.99\%) responded that dependence did not affect college performance, while $\mathrm{N}=337$ (96.01) responded that alcohol dependence negatively affected college performance. The last phase of the research examined the correlation between boredom, (dictated by social and friend isolation to avoid Covid-19 infections in the year 2020) and the AUDIT system (Fig. 3). Data analysis showed overall that boredom was felt by $\mathrm{N}=298(84.90 \%)$ college students and only $\mathrm{N}=53(15.10 \%)$ did not feel it. Regarding the relationship between boredom and "risk-free alcohol consumption," $\mathrm{N}=303(86.32 \%)$ college students related their alcohol behavior to boredom, while $\mathrm{N}=48$ (13.68\%) excluded boredom as the cause of their alcohol behavior, consuming it without associated risks; on the other hand, regarding the incidence of "boredom and "hazardous alcohol consumption", N=133 (37.89\%) students responded that boredom influenced their personal hazardous alcohol behavior, while $\mathrm{N}=218(62.11 \%)$ excluded this correlation; finally, students' evaluation of the possible correlation between "boredom and alcohol dependence" was investigated: $\mathrm{N}=72(20.51 \%)$ stated that boredom can generate alcohol dependence, $\mathrm{N}=279(79.49 \%)$ excluded this hypothesis.

\section{Acknowledgements}

I would like to thank the research group in "deviance and crime" of the University of Enna "Kore" for the important contribution during the phases of collection and processing of research data.

\section{Conclusion}

The COVID-19 pandemic, in addition to having modified the lifestyles, habits and behaviors of populations around the world, has certainly opened new fields of investigation and research, especially regarding the consequences of social isolation imposed by the governments of nations to avoid contagion. The present research investigated the correlation between alcoholic behavior (with AUDIT - Alcohol Use Disorders Identification Test) and low university performance, during Covid-19, in a sample of Italian university students, in order to understand if personal alcohol consumption has increased or decreased due to the restrictions imposed for an exceptional event such as the pandemic and if boredom (as a cause of the imposed social isolation) can generate or not alcoholic behaviors, which can represent especially for young people a dangerous "refuge", and to which they can also become "addicted". The results obtained show a clear tendency on the part of the sample used to consider alcohol as a dangerous factor that conditions the person and the course of his or her life. It is therefore necessary to reflect on the tools to be used, on motivational and personalized interventions to be adopted, on the use of effective policies by governments, both to reduce deviant behavior in complex situations such as a pandemic (alcohol being one of them), and to safeguard the health of young people. It would seem appropriate, in the event that other exceptional events occur in the future, to devote a few hours of training/information to university students on the topic of alcohol behavior, by experts. This survey was aimed at students at only one university, so in terms of limitation, the results may not be generalizable to students at other larger/smaller, public/private universities. Another limitation relates to the relatively small sample size $(\mathrm{N}=351)$ used in this research. The results presented could be considered preliminary until more robust research, with a larger sample and variables, could confirm the estimates obtained or produce new results. 


\section{References}

(1) Bränström R, Pachankis JE. Sexual orientation disparities in the co-occurrence of substance use and psychological distress: A national population-based study (2008-2015). Social Psychiatry and Psychiatric Epidemiology: The International Journal for Research in Social and Genetic Epidemiology and Mental Health Services 2018; 53(4): 403-412. https://doi.org/10.1007/s00127-018-1491-4.

(2) Burton R, Sheron N. No level of alcohol consumption improves health. Lancet 2018. 2392(10152): 987-988. doi: $10.1016 / \mathrm{S} 0140-6736(18) 31571-\mathrm{X}$.

(3) Calamai G. Substance use and abuse. Understanding and coping with alcohol and drug addictions. Trento (Italy): Erickson 2018

(4) Cao W, Fang Z, Hou G, et al. The psychological impact of the COVID-19 epidemic on college students in China. Psychiatry Research 2020. https://doi.org/10.1016/j.psychres.2020.112934.

(5) Censi V, Padrevecchi F, Salvador E. Alcohol abuse. When drinking drowns feeling. Milano (Italy): Hoeply 2019.

(6) Durkheim E. Suicide Moral education. Torino: Utet 2008.

(7) Galea S, Merchant RM, Lurie N. The mental health consequences of COVID-19 and physical distancing: The need for prevention and early intervention. JAMA Internal Medicine 2020; 180(6): 817-818. https://doi.org/10.1001/jamainternmed.2020.1562.

(8) Hassel A, Nordfjaern T, Hagen R. (2013). Psychological and interpersonal distress among patients with substance use disorders: Are these factors associated with continued drug use and do they change during treatment. Journal of Substance Use 2013; 18(5): 363-376.

(9) Li S, Wang Y, Xue J, et al. The Impact of COVID-19 Epidemic Declaration on Psychological Consequences: A Study on Active Weibo Users. Int. J. Environ. Res. Public Health 2020; 17, 2032. https://doi.org/10.3390/ijerph17062032.

(10) Lin SY, Fried EI, Eaton NR. The association of life stress with substance use symptoms: A network analysis and replication. Journal of Abnormal Psychology 2020; 129(2): 204-214.

(11) Lyers M, Cutinho D, Thorberg FA. Alexithymia, impulsivity, disordered social media use, mood and alcohol use in relation to Facebook self-disclosure. Computers in Human Behavior 2020; 103: 174-180.

(12) Martin K. Impact of COVID-19 on retail alcohol sales. Found on the World Wide Web 2020. https://www.winsightgrocerybusiness.com/center-store/impact-covid-19-retail-alcohol-sales.

(13) McIntyre RS, Lee Y. Preventing suicide in the context of the COVID-19 pandemic. World Psychiatry 2020; 19(2): 250-251. doi: 10.1002/wps.20767.

(15) National Institute of Drug Abuse (NIDA). National survey on drug use and health: Trends in prevalence of various drugs for ages 12 or older, ages 12 to 17, ages 18 to 25, and ages 26 or older; 2016-2018 (in percent) 2019. As found on the World Wide Web: https://www.drugabuse.gov/drug-topics/trends-statistics/national-drugearly-warning-system-ndews/national-survey-drug-use-health.

(16) Orgilés M, Morales A, Delvecchio E, et al. Immediate psychological effects of the COVID-19 quarantine in youth from Italy and Spain. (2020, April 21). https://doi.org/10.31234/osf.io/5bpfz 
(17) Ornell F, Ferreira Moura H, Nichterwitz Scherer J, et al. The COVID-19 pandemic and its impact on substance use: Implications for prevention and treatment. Psychiatry Research 2020; 289: 113096.

(18) Panagiotidis P, Rantis K, Holeva V, Parlapani E, et al. Changes in Alcohol Use Habits in the General Population, during the COVID-19 Lockdown in Greece. Alcohol and Alcholism 2020; 55 (6): 702-704. https://doi.org/10.1093/alcalc/agaa092.

(19) Qiu J, Shen B, Zhao M, et al. (2020). A nationwide survey of psychological distress among Chinese people in the COVID-19 epidemic: implications and policy recommendations. Gen Psychiatr. 2020; 27; 33(2).

(20) Sargent JD, Cukier S, Babor TF. Alcohol Marketing and Youth Drinking: Is There a Causal Relationship, and Why Does It Matter? Journal of Studies on Alcohol and Drugs 2020; 19: 5-12.

(21) Scott S, Muir C, Stead M, et al. Exploring the links between unhealthy eating behaviour and heavy alcohol use in the social, emotional and cultural lives of young adults (aged 18-25): A qualitative research study. Appetite 2020; 144. https://doi.org/10.1016/j.appet.2019.104449.

(22) Sola V, Sakiyama HMT, Rato Padin MDF, Canfield M, et al. Measuring stress, coping, strain, and hopefulness of Brazilian family members of substance misusers: Factor structure of a set of measures. Journal of Substance Use 2019; 24(2): 130-139.

(23) Substance Abuse and Mental Health Services Administration (SAMHSA). Substance use disorder treatment for people with co-occurring disorders. US Department of Health and Human Services 2020. https://store.samhsa.gov/product/tip-42-substance-use-treatment-persons-co-occurring-disorders/PEP20-02-01$\underline{004}$.

(24) Walker DD, Jaffe AE, Pierce AR, et al. (2020). Discussing substance use with clients during the COVID19 pandemic: A motivational interviewing approach. Psychological Trauma Theory Research Practice and Policy 2020; 12(S1: S115-S117). 